\title{
American ginseng berry enhances chemopreventive effect of 5-FU on human colorectal cancer cells
}

\author{
XIAO-LI LI ${ }^{1,2}$, CHONG-ZHI WANG ${ }^{1,2}$, SHI SUN ${ }^{1,2}$, SANGEETA R. MEHENDALE ${ }^{1,2}$, \\ WEI DU ${ }^{3}$, TONG-CHUAN HE ${ }^{4}$ and CHUN-SU YUAN ${ }^{1,2,5}$
}

\author{
${ }^{1}$ Tang Center for Herbal Medicine Research, ${ }^{2}$ Department of Anesthesia and Critical Care, ${ }^{3}$ Ben May Department of \\ Cancer Research, ${ }^{4}$ Molecular Oncology Laboratory, Department of Surgery, ${ }^{5}$ Committee on Clinical Pharmacology \\ and Pharmacogenomics, The Pritzker School of Medicine, University of Chicago, Chicago, IL 60637, USA
}

Received May 4, 2009; Accepted June 22, 2009

DOI: $10.3892 /$ or_00000521

\begin{abstract}
In this study, we investigated the possible synergistic chemopreventive effects of American ginseng berry extract (AGBE) and 5-fluorouracil (5-FU) on human colorectal cancer cell lines, SW-480, HCT-116 and HT-29. We used high-performance liquid chromatography to determine the contents of major ginsenosides, the active components of American ginseng, in AGBE. The antiproliferative effects were evaluated by the cell counting method. AGBE $(0.1-1.0 \mathrm{mg} / \mathrm{ml})$ significantly inhibited SW480 , HCT-116 and HT-29 cell growth in a concentrationdependent manner. Cell growth decreased more with the combined treatment of 5-FU and AGBE than with 5-FU or AGBE applied alone, suggesting that AGBE can reduce the dose of 5-FU needed to achieve desired effects and thereby decrease the dose-related toxicity of the chemotherapy agent. Cell apoptosis assay showed that AGBE markedly reduced the number of viable SW-480 cells at 0.5 and $1.0 \mathrm{mg} / \mathrm{ml}$, but did not increase cell apoptosis significantly. Neither 5-FU nor co-treatment with 5-FU and AGBE induced cell apoptosis markedly. Cell cycle assay showed that AGBE mainly arrested SW-480 cells in the G2/M phase. 5-FU increased the percentage of SW-480 cells at the S phase of the cell cycle. The assay of combined treatment groups indicated that AGBE can heighten the arrest of SW-480 cells in the S phase induced by $5-\mathrm{FU}$, and increase the cell distribution in $\mathrm{G} 2 / \mathrm{M}$ phase compared with 5-FU applied alone. The trend of increasing cyclin A was similar to the increase of S and G2/M phase cells in all treated groups. The enhancement of $S$ and $\mathrm{G} 2 / \mathrm{M}$ phase arrest, rather than cell apoptosis, should be the
\end{abstract}

Correspondence to: Dr Chun-Su Yuan, Tang Center for Herbal Medicine Research, and Department of Anesthesia \& Critical Care, Pritzker School of Medicine, University of Chicago, 5841 South Maryland Avenue, MC 4028, Chicago, IL 60637, USA

E-mail: cyuan@dacc.uchicago.edu

Key words: American ginseng, human colorectal cancer, antiproliferation, apoptosis, cell cycle, cyclin A, 5-fluorouracil mechanism of synergistic effects of AGBE on 5-FU. Further in vivo and clinical trials are needed to test $\mathrm{AGBE}$ as a valuable chemo-adjuvant.

\section{Introduction}

Colorectal cancer is one of the most common malignancies and ranks as the second greatest cause of cancer death in both men and women worldwide (1). Although early stage colorectal cancer can be cured by surgical resection, surgery is often combined with adjuvant radiotherapy and chemotherapy with one or more chemotherapeutic agents. Even with effective strategies that continue to be developed for treating colorectal cancer, chemotherapy has the drawbacks of severe adverse effects and dose-limiting toxicity. Drug-related adverse events not only worsen patients' quality of life, but can also lead to their refusal to continue chemotherapy $(2,3)$. Chemotherapy-induced toxicity can be reduced by chemoadjuvant compounds that potentiate tumoricidal effects with lower doses (4-6). Identifying non-toxic chemo-adjuvants among herbal medicines may be an essential step in advancing the treatment of cancer (7).

Due to the increase in the consumption of herbal remedies in the United States along with a staggering popularity of the ginseng herb as a method of sustaining good health, significant focus has been placed on American ginseng (Panax quinquefolius L.) (8), which belongs to the genus Panax L. in the Araliaceae family. American ginseng has been reported to have stress-relieving qualities, anti-aging effects and digestion-aiding effects (9). Cancer treatment with botanicals like American ginseng has also received increasing attention in recent years (10-13). The major active components of ginseng are ginsenosides, a diverse group of steroid saponins. Ginsenosides are distributed in many parts of the ginseng plant, including the root, leaf and berry. The most commonly used part of the plant is the root, which is harvested in late summer to fall between its fourth and seventh years (14). As a byproduct, American ginseng berry can be harvested more than once before harvesting the root. Previous study has demonstrated that the berry has a significantly higher content of total ginsenosides than the root of ginseng (15) and has a ginsenoside profile distinct from that of the root (16). The 
pharmacological effects of ginseng berries have been evaluated. It is well documented that American ginseng berry extract (AGBE) could improve diabetic conditions (17), such as decreasing the blood glucose and body weight in ob/ob mice $(18,19)$, attenuating oxidant stress in cardiomyocytes $(20)$, reducing chemotherapy-induced nausea/vomiting (21), and exerting antiproliferative activity against human breast carcinoma cells (22). Previously, our laboratory analyzed ginsenoside compounds in AGBE with different processing methods, and pilot data showed the effects on colorectal cancer cells (23). However, the mechanism of the antiproliferative effect of AGBE is not known.

5-Fluorouracil (5-FU) is one of the most widely used chemotherapeutic agents in first-line therapy for colorectal cancer $(24,25)$, and an overall survival benefit after fluorouracil-based chemotherapy has been firmly established (26). But for the treatment of metastatic colon cancer, however, higher 5-FU doses produced more adverse effects while not necessarily being more effective than lower doses (27). Therefore, if decreasing the dose of chemotherapy and increasing its anti-cancer effect could be accomplished by combining 5-FU with other agents, patients may benefit. However, chemotherapy with 5-FU and herbal medicines has rarely been studied.

Thus, this study investigated the potential synergistic tumoricidal effects of AGBE on 5-fluorouracil (5-FU). We used various human colorectal cancer cell lines, SW-480, HCT-116 and HT-29, which have undergone extensive laboratory cancer research and have been the models for the cellular pathways studies of chemotherapy on cancer cells. Furthermore, we observed the combined effect on cell apoptosis, cell cycle and cycle A in SW-480 cells to elucidate the possible mechanism in these cells. This is an important preliminary step in the development of an effective chemoadjuvant for colorectal cancer treatment.

\section{Materials and methods}

Chemicals. All solvents were of high-performance liquid chromatography (HPLC) grade from Fisher Scientific (Norcross, GA). Milli Q water was supplied by a water purification system (US Filter, Palm Desert, CA). Standards for ginsenosides Rb1, Rb2, Rb3, Rc, Rd, Re, Rg1 and Rg3 were obtained from the Delta Information Center for Natural Organic Compounds (Xuancheng, Anhui, China). All standards were of biochemical-regent grade and at least $95 \%$ pure as confirmed by HPLC. All cell culture plasticware was purchased from Falcon Labware (Franklin Lakes, NJ) and Techno Plastic Products (Trasadingen, Switzerland). Trypsin, McCoy's 5A medium, Leibovitz's L-15 medium, fetal bovine serum (FBS), and phosphate-buffered saline (PBS) were obtained from Mediatech, Inc. (Herndon, VA). 5-Fluorouracil (5-FU) was obtained from American Pharmaceutical Partners Inc. (Schaumburg, IL). Penicillin G/streptomycin was obtained from Sigma (St. Louis, MO). An Annexin V-FITC Apoptosis Detection kit was obtained from BD Biosciences (Rockville, MD). PI/RNase staining buffer was supplied from BD Biosciences Pharmingen (San Diego, CA).

Herbal materials and sample preparation. Fresh berry of American ginseng (Panax quinquefolius L.) was obtained from Roland Ginseng, LLC (Wausau, WI, USA). All berries were gathered from 4-year-old plants. The seeds of the berry were removed and lyophilized to obtain dried pulp sample. The berry pulp was ground to powder and extracted with $70 \%$ ethanol for $4 \mathrm{~h}$; the water bath was maintained at $90^{\circ} \mathrm{C}$. When cooled, the solution was filtered and the filtrate was collected. The residue was extracted with $70 \%$ ethanol once more and then filtered while the solution was cooled. The filtrates were combined and the solvent was evaporated under vacuum to obtain the primary extract. The primary extract was further purified to obtain American ginseng berry extract.

High-performance liquid chromatographic analysis. Highperformance liquid chromatography (HPLC) analysis was conducted on a Waters HPLC system (Milford, MA, USA). This HPLC system was composed of a Waters 2960 instrument, a quaternary pump, an automatic injector, and a photodiode array detector (Model 996). The separation was carried out on a $250 \times 3.2 \mathrm{~mm}$ i.d., $5 \mu$, Ultrasphere C18 column (Alltech, Deerfield, IL, USA) with a 7.5x3.2 mm i.d. guard column. For the mobile phase, acetonitrile (solvent A) and water (solvent B) were used, and flow rate was $1.0 \mathrm{ml} / \mathrm{min}$. Gradient elution started with $18 \%$ solvent $\mathrm{A}$ and $82 \%$ solvent B. Elution was changed to $21 \%$ A for $20 \mathrm{~min}$, then to $26 \% \mathrm{~A}$ for $3 \mathrm{~min}$ and held for $19 \mathrm{~min}$. It was then changed to $36 \% \mathrm{~A}$ for $13 \mathrm{~min}$, to $50 \% \mathrm{~A}$ for $9 \mathrm{~min}$, to $95 \% \mathrm{~A}$ for $2 \mathrm{~min}$, and held for $3 \mathrm{~min}$, to $18 \%$ A for $3 \mathrm{~min}$ and held for $8 \mathrm{~min}$. The detection wavelength was set to $202 \mathrm{~nm}$. Regression equations of ginsenosides Rb1, Rb2, Rb3, Rc, Rd, Re, Rg1 and Rg3 were prepared using standard solutions within different concentrations. For the sample assay, $20 \mu 1$ of $2 \mathrm{mg} / \mathrm{ml}$ of extract solution was injected, and the assay was repeated 3 times. All solutions were filtered through Millex $0.2 \mu \mathrm{M}$ nylon membrane syringe filters (Millipore Co., Bedford, MA, USA) before use.

Cell culture. SW-480, HCT-116 and HT-29 human colorectal cancer cells (ATCC, Manassas, VA) were routinely grown in a humidified atmosphere of $5 \% \mathrm{CO}_{2}$ at $37^{\circ} \mathrm{C}$ in Leibovitz's L-15 medium (for SW-480) and in McCoy's 5A medium (for HCT-116 and HT-29), respectively, supplemented with $10 \%$ fetal bovine serum and 50 IU penicillin/streptomycin. Cells were grown in a $25-\mathrm{ml}$ flask and were routinely subcultured using $0.05 \%$ trypsin-EDTA solution. Cells were maintained at the culture conditions described above for all experiments.

Cell proliferation assay. To examine the antiproliferation effect of the test agents, SW-480, HCT-116 and HT-29 cells were seeded in 24-well plates at approximately $1 \times 10^{4}$ cells/ well with regular Leibovitz's L-15 or McCoy's 5A medium, respectively, and allowed to adhere for $24 \mathrm{~h}$. Then fresh culture media were changed prior to the addition of drugs. The SW-480, HCT-116 and HT-29 cells were incubated with $\operatorname{AGBE}(0.1,0.5$ and $1.0 \mathrm{mg} / \mathrm{ml})$; or 5 -FU $(10 \mu \mathrm{M})$; or both drugs for $72 \mathrm{~h}$. Control cultures were incubated in medium containing vehicle alone. At the end of treatments, the cell monolayer was washed twice with phosphate-buffered saline (PBS). Cultures were harvested and monitored for number by using a Coulter cell counter (Coulter Electronics, Inc., Hialeah, FL). All assays were performed at least 3 times. The percentage of cell proliferation was calculated as follows: 


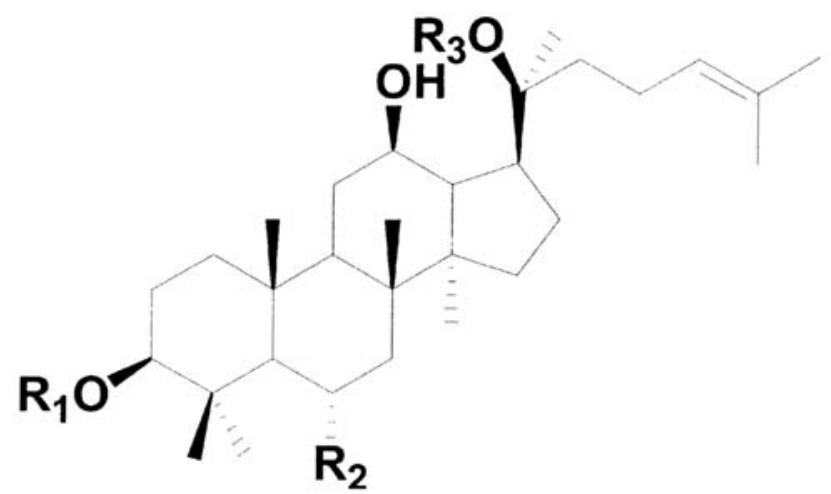

\begin{tabular}{cccc}
\hline Name & $\mathrm{R} 1$ & $\mathrm{R2}$ & $\mathrm{R3}$ \\
\hline Ginsenoside $\mathrm{Rg}_{1}$ & $-\mathrm{H}$ & -0 -glc & -glc \\
Ginsenoside $\mathrm{Re}$ & $-\mathrm{H}$ & - 0-glc-glc & -glc \\
Ginsenoside $\mathrm{Rb}_{1}$ & -glc-glc & $-\mathrm{H}$ & -glc-glc \\
Ginsenoside $\mathrm{Rc}$ & -glc-glc & $-\mathrm{H}$ & -glc-ara (fur) \\
Ginsenoside $\mathrm{Rb}_{2}$ & -glc-glc & $-\mathrm{H}$ & -glc-ara (pyr) \\
Ginsenoside $\mathrm{Rb}_{3}$ & -glc-glc & $-\mathrm{H}$ & -glc-xyl \\
Ginsenoside $\mathrm{Rd}$ & -glc-glc & $-\mathrm{H}$ & -glc \\
Ginsenoside $\mathrm{Rg}_{3}$ & -glc-glc & $-\mathrm{H}$ & $-\mathrm{H}$ \\
\hline
\end{tabular}

Figure 1.Chemical structures of ginsenosides in American ginseng berry extract.

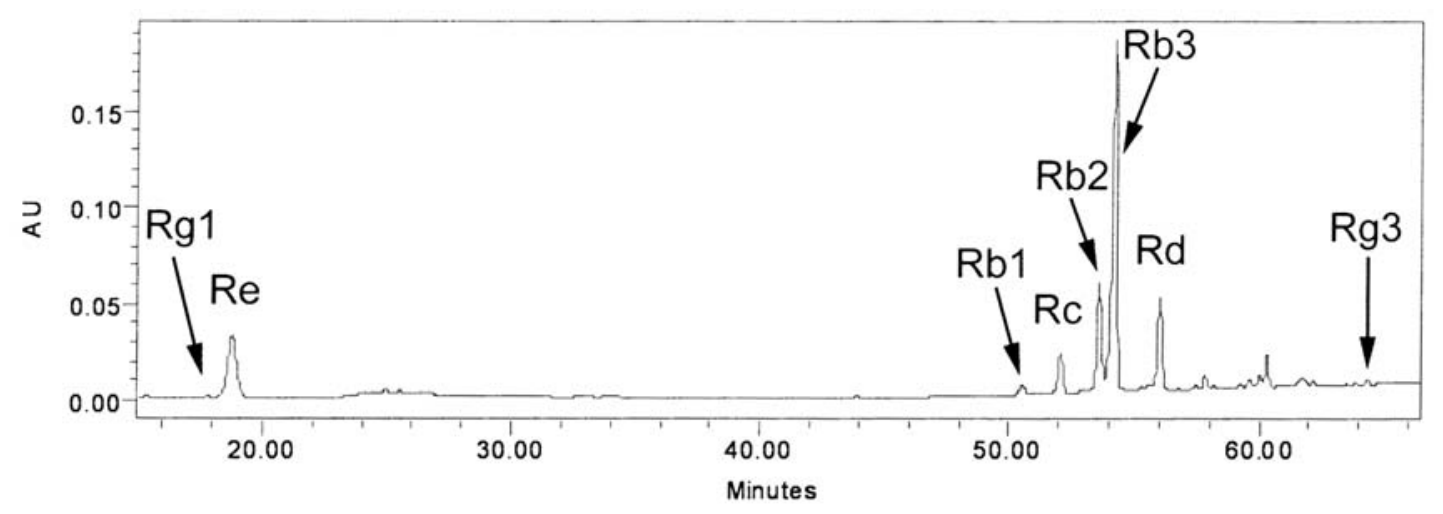

Saponin content in American ginseng berry extract (mean $\pm S D, n=3$ )

\begin{tabular}{ccccccccc}
\hline Ginsenoside & $\mathrm{Rg} 1$ & $\mathrm{Re}$ & $\mathrm{Rb} 1$ & $\mathrm{Rc}$ & $\mathrm{Rb} 2$ & $\mathrm{Rb} 3$ & $\mathrm{Rd}$ & $\mathrm{Rg} 3$ \\
\hline Content $(\%)$ & $0.14 \pm 0.01$ & $6.86 \pm 0.02$ & $0.57 \pm 0.02$ & $3.06 \pm 0.03$ & $6.98 \pm 0.05$ & $24.54 \pm 0.28$ & $4.76 \pm 0.07$ & $0.15 \pm 0.01$ \\
\hline
\end{tabular}

Figure 2. HPLC analysis of American ginseng berry extract.

Cell proliferation $(\%)=($ cell number in each experimental well/average cell number in the control well) x100.

Apoptosis analysis. For apoptosis detection, floating cells in the medium and adherent cells were collected after 24,48 or $72 \mathrm{~h}$ of treatment with $\mathrm{AGBE}(0.5$ and $1.0 \mathrm{mg} / \mathrm{ml})$; or 5 -FU $(10 \mu \mathrm{M})$; or both. Using an Annexin V-FITC Apoptosis Detection kit, cells were stained with Annexin-V FITC and propidium iodide (PI) according to the manufacturer's instructions. Untreated SW-480 cells were used as the control for double staining. Cells were analyzed immediately by using a flow cytometer (Becton-Dickinson, Mountain View, CA). For each measurement, at least 20,000 cells were counted.

Cell cycle and cyclin A analysis. SW-480 cells were plated at a density of $2 \times 10^{5}$ cells onto 24 -well plates. The medium was replaced $24 \mathrm{~h}$ after seeding with fresh medium containing AGBE $(0.5 \mathrm{mg} / \mathrm{ml})$; or $5-\mathrm{FU}(10 \mu \mathrm{M})$; or both. To analyze the cell cycle distribution, cells were trypsinized after 24,48 or $72 \mathrm{~h}$ of exposure to these samples, fixed gently with $80 \%$ ethanol, and stored at $-20^{\circ} \mathrm{C}$ for $2 \mathrm{~h}$. Then they were treated with $0.25 \%$ Triton $\mathrm{X}-100$ for $5 \mathrm{~min}$ in an ice bath. The cells 

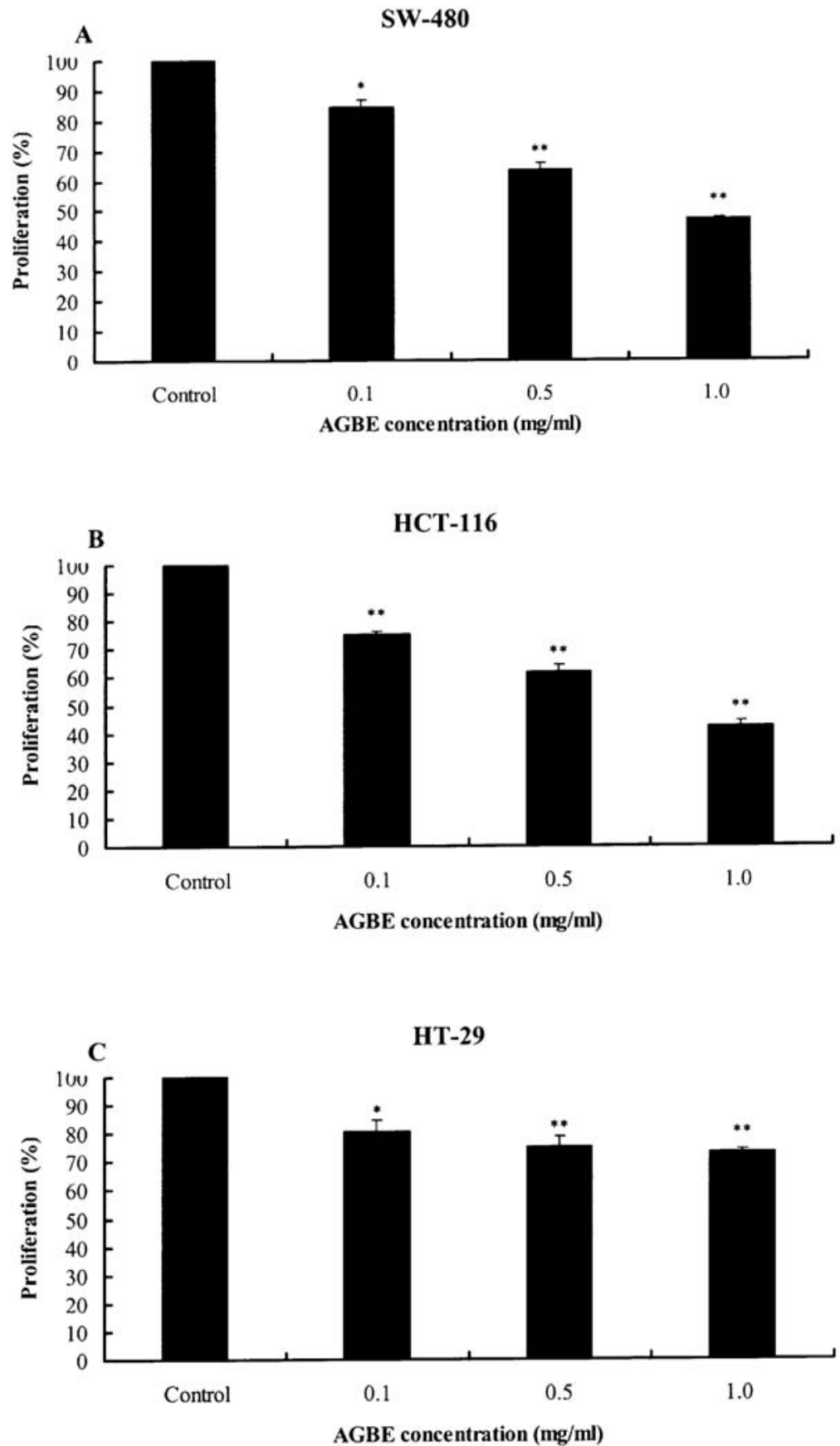

Figure 3. Antiproliferative effects of American ginseng berry extract (AGBE, $0.1,0.5$ and $1.0 \mathrm{mg} / \mathrm{ml}$ ) on the human colorectal cancer cells after $72 \mathrm{~h}$ of treatment. These data indicated that AGBE inhibited the proliferation of human colon cancer SW-480 (A), HCT-116 (B) and HT-29 (C) cells significantly in a concentration-dependent manner. Data are presented as the mean \pm standard error of mean of triplicate experiments. ${ }^{*} \mathrm{P}<0.05,{ }^{* *} \mathrm{P}<0.01$, vs. control.

were resuspended in $300 \mu \mathrm{l}$ of PBS containing $40 \mu \mathrm{g} / \mathrm{ml}$ propidium iodide (PI) and $0.1 \mathrm{mg} / \mathrm{ml}$ RNase. Then $20 \mu \mathrm{l}$ of cyclin A-FITC was added to the cell suspension. Cells were incubated in a dark room for $20 \mathrm{~min}$ at room temperature and analyzed with a flow cytometer. For each measurement, at least 10,000 cells were counted.

Statistical analysis. Results are presented as mean \pm standard error (SE). Data were analyzed using Student's t-test and analysis of variance (ANOVA) for repeated measures. The level of statistical significance was set at $\mathrm{P}<0.05$.

\section{Results}

HPLC analysis of AGBE. Saponins in American ginseng berry extract (AGBE) were identified by observing the retention times and UV spectrum of authentic ginsenoside $\mathrm{Rb} 1, \mathrm{Rb} 2, \mathrm{Rb} 3, \mathrm{Rc}, \mathrm{Rd}, \mathrm{Re}, \mathrm{Rg} 1$ and Rg3 standards obtained from the mixed standards chromatograms. The chemical structures of identified saponins were shown in Fig. 1. Fig. 2 showed representative HPLC chromatograms of AGBE recorded at $202 \mathrm{~nm}$ and the HPLC analysis of the contents of saponins in AGBE. 

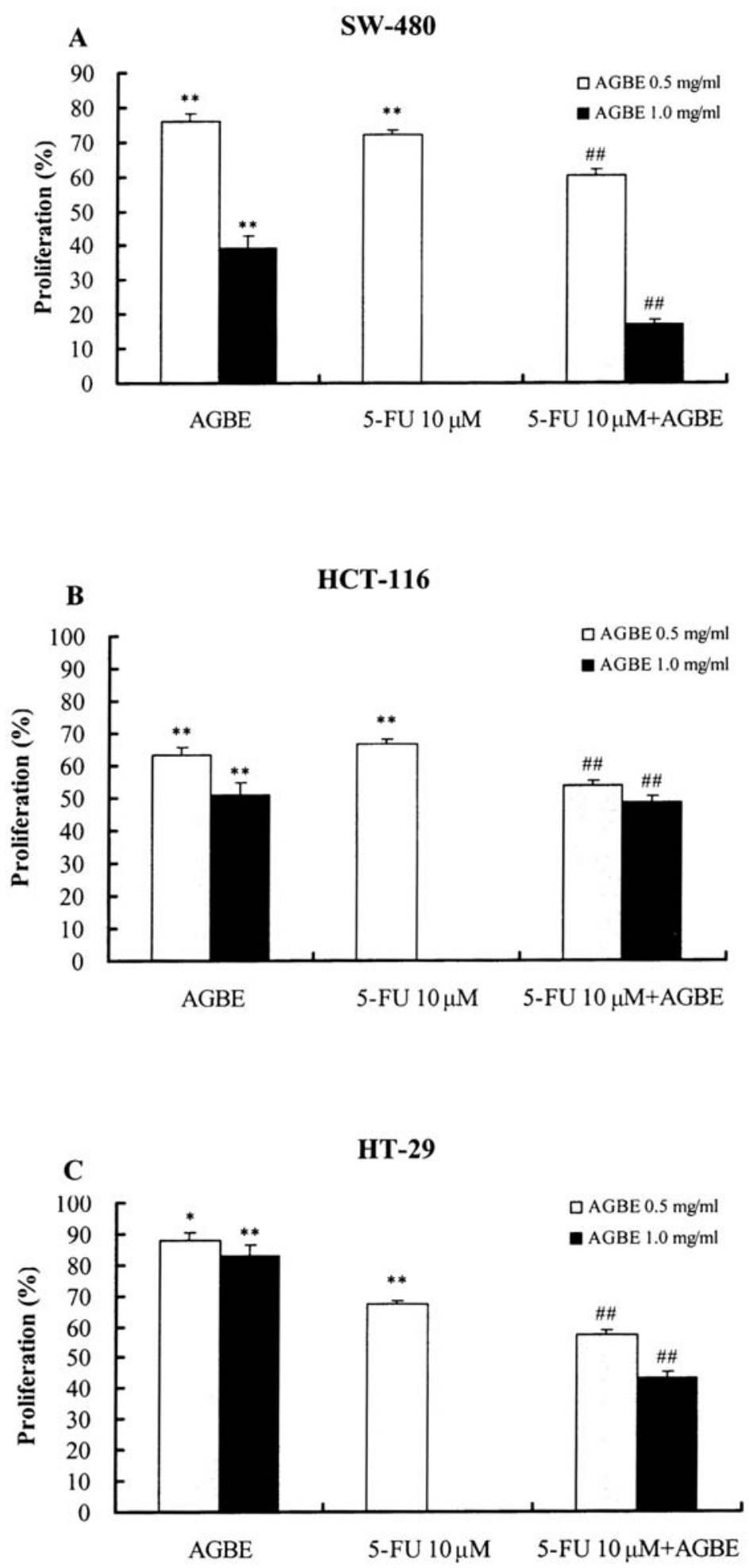

Figure 4. Antiproliferatve effects of American ginseng berry extract (AGBE, 0.5 and $1.0 \mathrm{mg} / \mathrm{ml}$ ) combined with chemotherapeutic agent 5-fluorouracil (5-FU, $10 \mu \mathrm{M}$ ) on human colorectal cancer SW-480 (A), HCT-116 (B) and HT-29 (C) cells after $72 \mathrm{~h}$ treatment. Data are presented as the mean \pm standard error of mean of triplicate experiments. ${ }^{*} \mathrm{P}<0.05,{ }^{* *} \mathrm{P}<0.01$, vs. control; ${ }^{\# \#} \mathrm{P}<0.01$, vs. 5 -FU alone.

Effects of AGBE on SW-480, HCT-116 and HT-29 cell proliferation. The antiproliferative effects of AGBE $(0.1,0.5$ and $1.0 \mathrm{mg} / \mathrm{ml}$ ) on SW-480, HCT-116 and HT-29 human colorectal cancer cells are shown in Fig. 3. After treat-ment for $72 \mathrm{~h}$, AGBE significantly inhibited SW-480 cell proliferation (Fig. 3A). The extract reduced SW-480 cell growth in a concentration-dependent manner, by $15.4 \pm 1.9 \%$ at $0.1 \mathrm{mg} / \mathrm{ml}(\mathrm{P}<0.05), 36.5 \pm 2.3 \%$ at $0.5 \mathrm{mg} / \mathrm{ml}(\mathrm{P}<0.01)$, and $52.9 \pm 0.6 \%$ at $1.0 \mathrm{mg} / \mathrm{ml}(\mathrm{P}<0.01)$, compared with control group (normalized to $100 \%$ ). Similar results were observed from HCT-116 and HT-29 cell lines (Fig. 3B and C). These data suggested the dose-dependent antiproliferative effect of AGBE on human colorectal cancer cells in vitro experiments. 
$24 \mathrm{~h}$

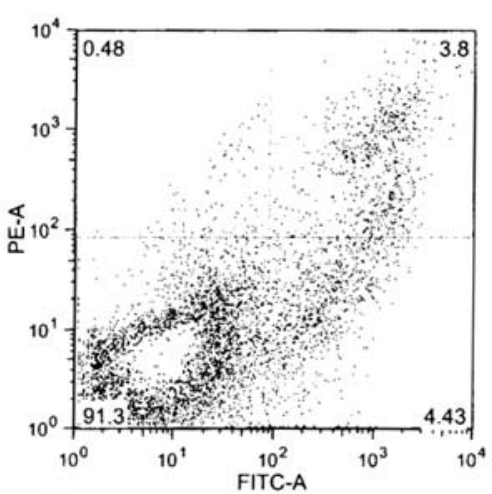

$48 \mathrm{~h}$

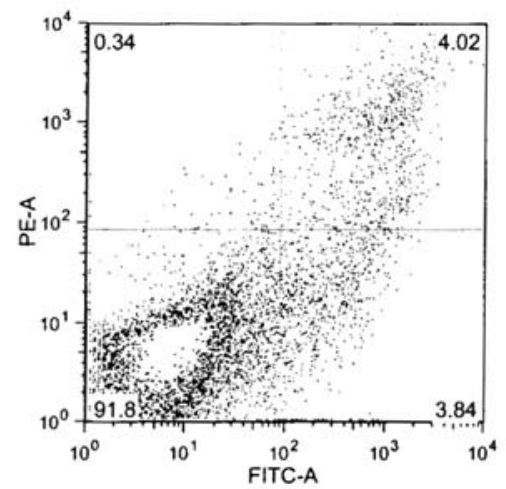

$72 \mathrm{~h}$

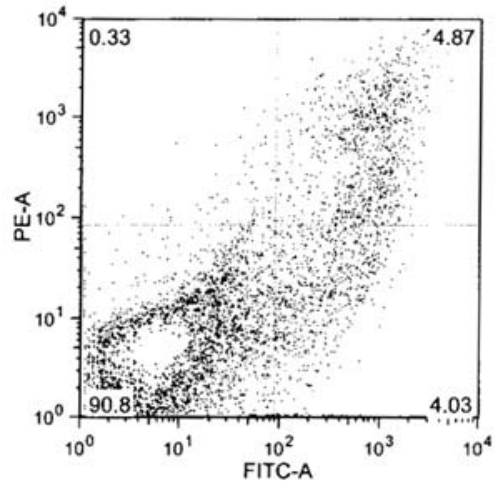

Control
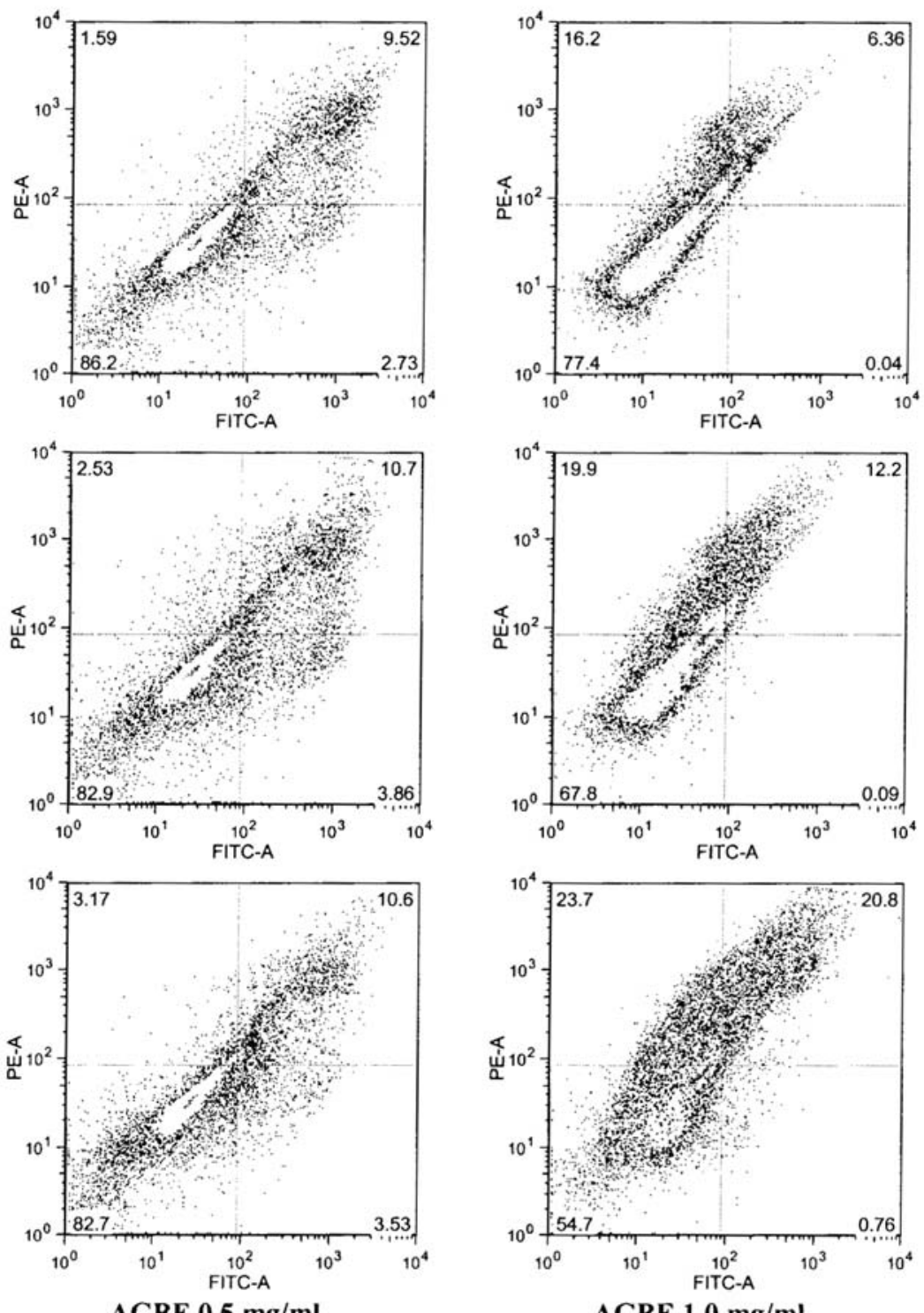

AGBE $0.5 \mathrm{mg} / \mathrm{ml}$

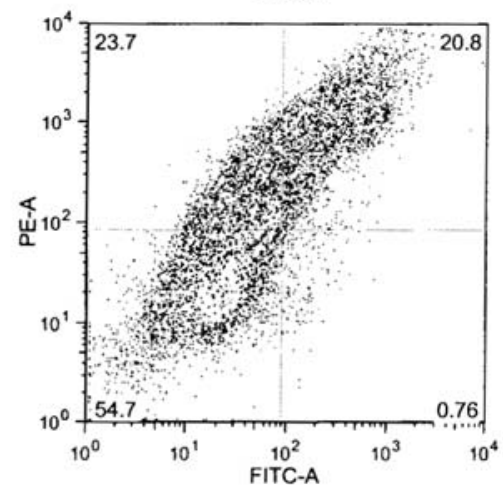

AGBE $1.0 \mathrm{mg} / \mathrm{ml}$

Figure 5. Apoptosis assay of SW-480 cells treated with American ginseng berry extract (AGBE). SW-480 cells were treated with $0.5 \mathrm{and} 1.0 \mathrm{mg} / \mathrm{ml}$ AGBE for 24,48 and $72 \mathrm{~h}$. The percentage of different types of cells is shown. Data shown are from two independent experiments.

Effect of 5-FU combined with AGBE on SW-480, HCT-116 and HT-29 cell proliferation. The influence of AGBE on 5fluorouracil (5-FU)-induced antiproliferation in human colorectal cancer cells is shown in Fig. 4. Fig. 4A shows that when treated alone for $72 \mathrm{~h}, 5-\mathrm{FU}$, at the concentration of $10 \mu \mathrm{M}$, decreased SW-480 cell growth by $21.8 \pm 1.3 \%$ $(\mathrm{P}<0.01$, compared with control). Combined treatment of AGBE at the concentration of 0.5 or $1.0 \mathrm{mg} / \mathrm{ml}$ with $5-\mathrm{FU}$ further decreased the SW-480 cell growth by $39.7 \pm 1.8 \%$ and $83.0 \pm 1.6 \%$, respectively (both $\mathrm{P}<0.01$, compared with 5 -FU alone).

The enhanced antiproliferative effects were also observed in HCT-116 (Fig. 4B) and HT-29 (Fig. 4C) cells after cotreatment for $72 \mathrm{~h}$. Data showed that 5-FU $(10 \mu \mathrm{M})$ significantly decreased HCT-116 and HT-29 cell growth by $33.3 \pm 1.3 \%$ and $32.7 \pm 1.3 \%$, respectively (both $\mathrm{P}<0.01$, compared with control group). The suppressive effect of cotreatment with 5-FU and AGBE was significantly stronger than that of 5-FU or AGBE alone as demonstrated; the combined treatment reduced the cell growth by $46.4 \pm 1.6 \%$ and $51.6 \pm 2.0 \%$ in HCT-116 cells and by $42.8 \pm 1.5 \%$ and $56.6 \pm 1.9 \%$ in HT-29 cells at the dose of AGBE $0.5 \mathrm{mg} / \mathrm{ml}$ and $1.0 \mathrm{mg} / \mathrm{ml}$, respectively (all $\mathrm{P}<0.01$, compared with $5-\mathrm{FU}$ alone). These results suggested that AGBE markedly enhanced 5-FU-induced antiproliferative effect on colorectal cancer cells.

Apoptotic effect of AGBE and/or 5-FU on SW-480 cells. To examine whether proliferation inhibition in treated cells was caused by the induction of apoptosis, we used flow cytometric analysis. The cytograms of bivariate Annexin V/ PI analysis of SW-480 cells after treatment with AGBE are shown in Fig. 5. Viable cells were negative for both PI and Annexin V (lower left quadrant); early apoptotic cells were positive for Annexin $\mathrm{V}$ and negative for PI (lower right quadrant); late apoptotic or necrotic cells displayed both positive for Annexin V and PI (upper right quadrant); nonviable cells which underwent necrosis were positive for PI and negative for Annexin V (upper left quadrant). Compared 

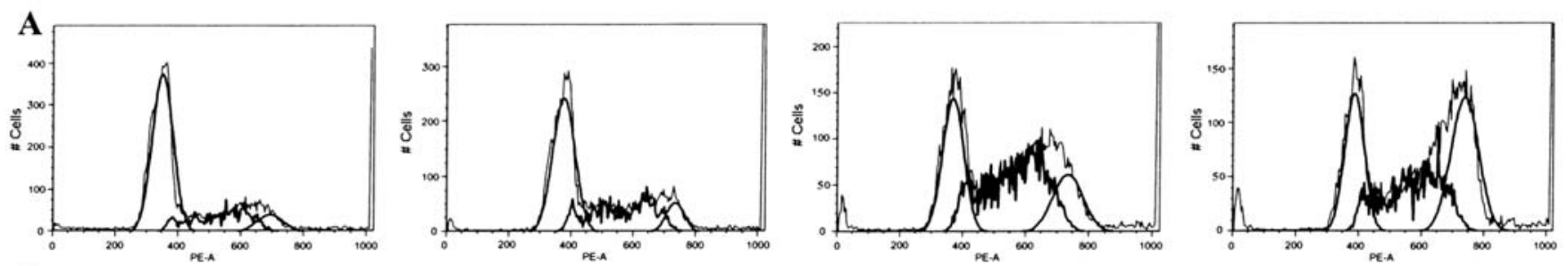

B
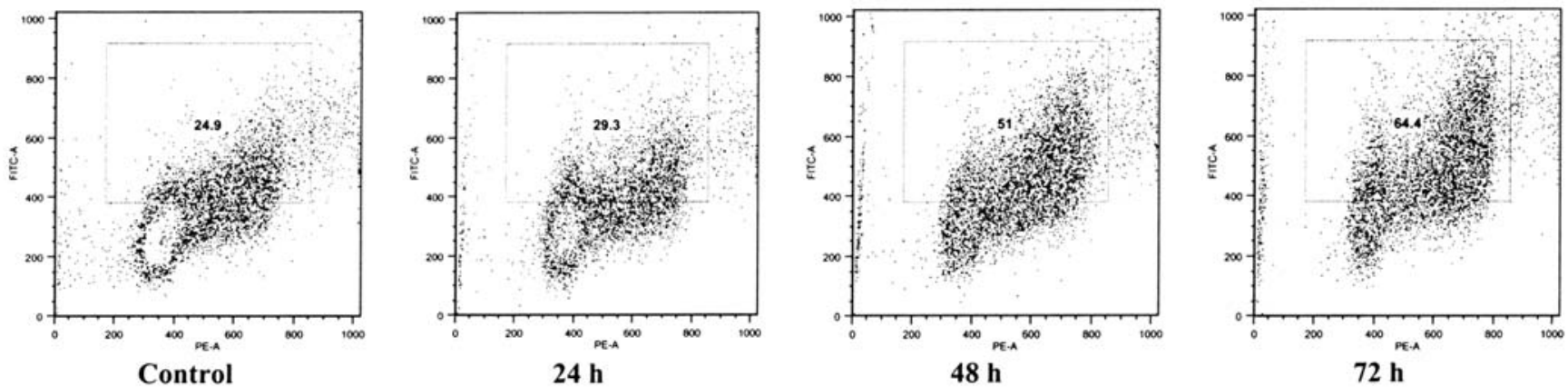

Figure 6. Cell cycle and cyclin A analysis of SW-480 cells treated with American ginseng berry extract (AGBE). SW-480 cells were treated with 0.5 and $1.0 \mathrm{mg} / \mathrm{ml} \mathrm{AGBE}$ for 24, 48 and $72 \mathrm{~h}$. (A) Cell cycle profiles of SW-480 cells. (B) SW-480 cells stained with cyclin A-FITC and proidium iodide. The percentage of cyclin A positive cells is shown in the gate. Data shown are from two independent experiments.

$24 \mathrm{~h}$

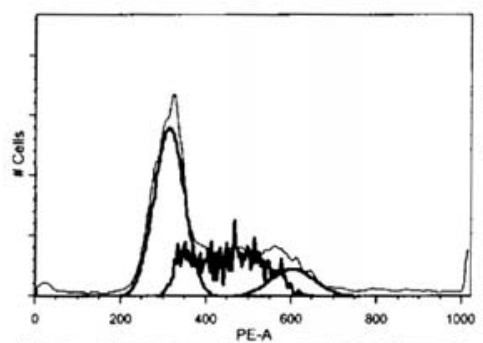

$48 \mathrm{~h}$

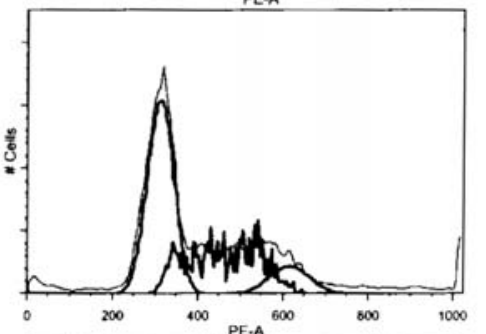

$72 \mathrm{~h}$

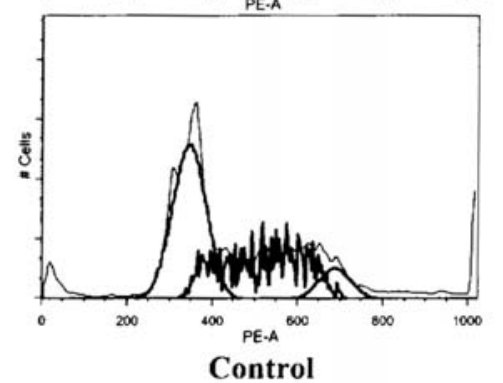

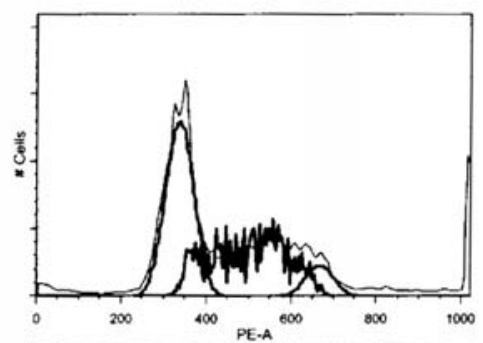
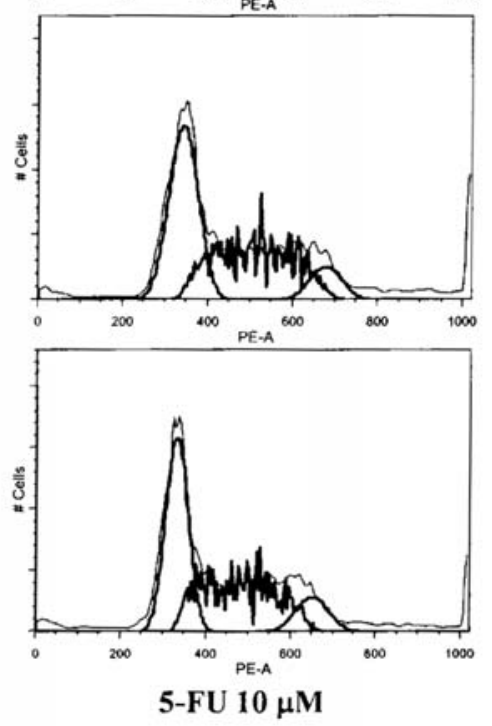
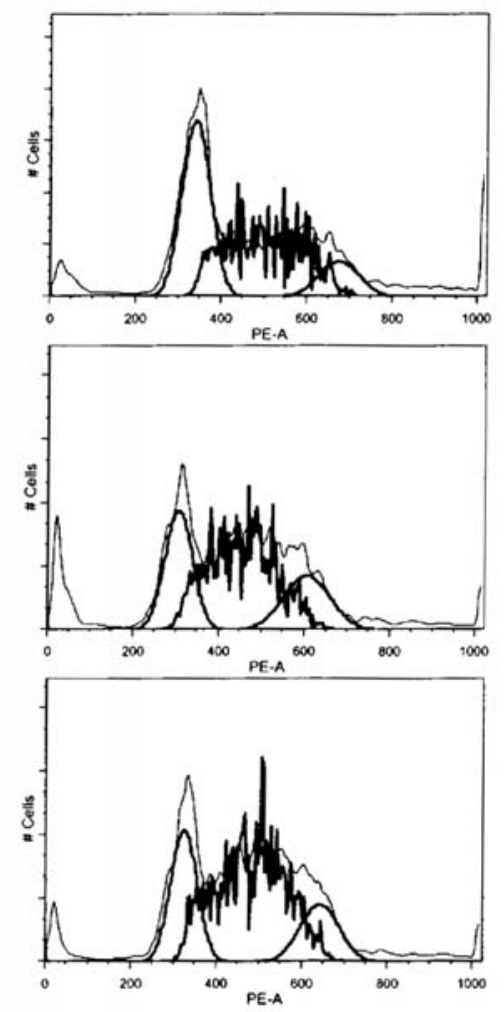

5-FU $10 \mu \mathrm{M}+$ AGBE $0.5 \mathrm{mg} / \mathrm{ml}$

Figure 7. The effect of American ginseng berry extract (AGBE) on 5-fluorouracil (5-FU)-induced cell cycle arrest. SW-480 human colorectal cancer cells were treated with 5-FU $(10 \mu \mathrm{M})$ with the absence or presence of AGBE $(0.5,1.0 \mathrm{mg} / \mathrm{ml})$ for 24,48 and $72 \mathrm{~h}$. The cell cycle was assessed using PI/RNase staining and flow cytometric analysis. Data shown are from two independent experiments.

to the untreated control $(72 \mathrm{~h}$ early apoptosis $4.03 \%$, late apoptosis/necrosis $4.9 \%$ ), AGBE increased late apoptosis/ necrosis to $20.8 \%$ and decreased early apoptosis to $0.8 \%$ after treatment with $1.0 \mathrm{mg} / \mathrm{ml}$ for $72 \mathrm{~h}$. On the other hand, the viable cell was $90.8 \%$ in control group and $82.7 \%$ and $54.7 \%$ in AGBE group $(0.5 \mathrm{mg} / \mathrm{ml}$ and $1.0 \mathrm{mg} / \mathrm{ml}$, respectively) after exposure of $72 \mathrm{~h}$. The similar trend was observed in AGBE treated groups at other time points. These 

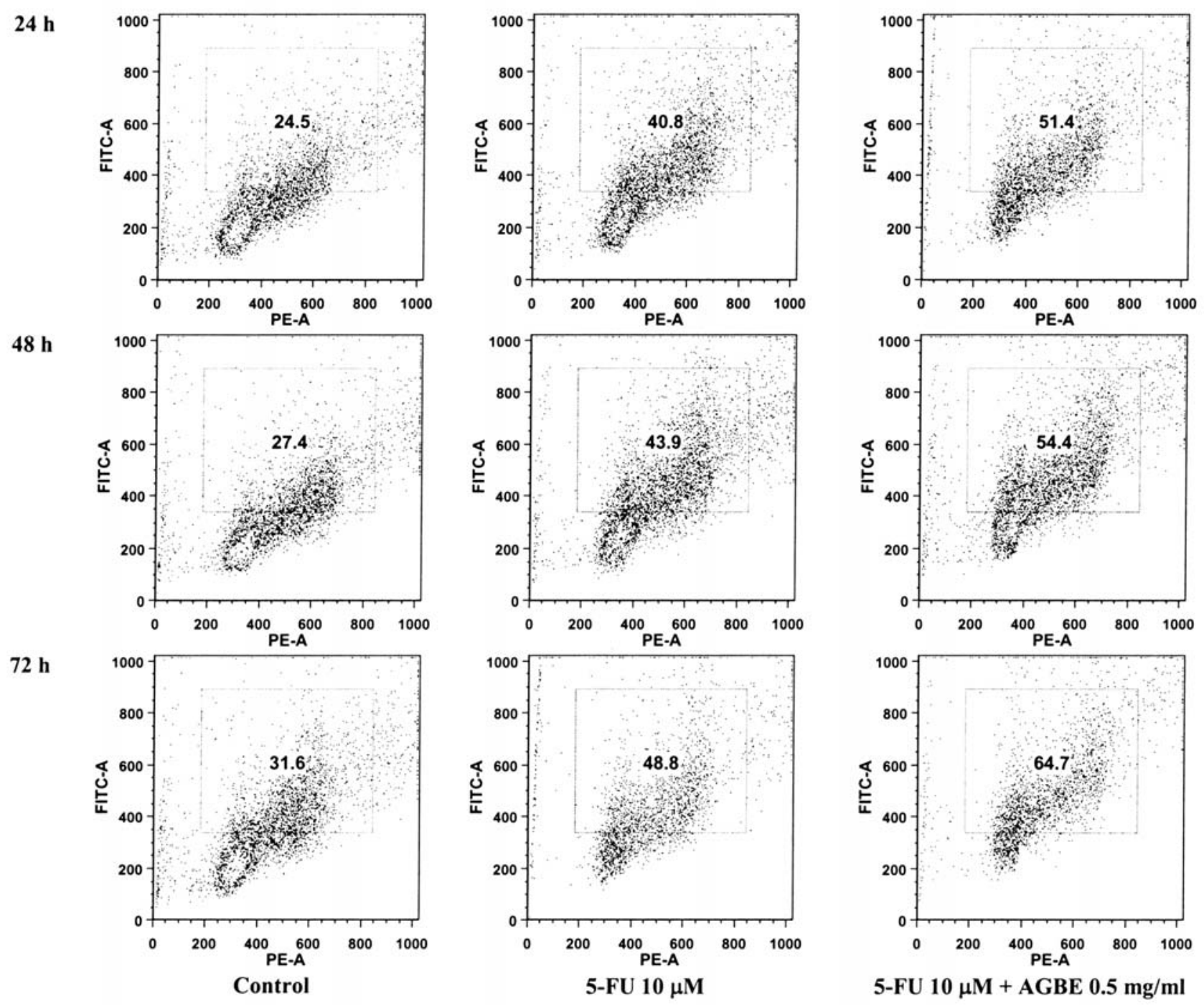

Figure 8. Cyclin A analysis of SW-480 cells treated with 5-fluorouracil (5-FU) alone or combined with American ginseng berry extract (AGBE). SW-480 human colorectal cancer cells were treated with 5-FU $(10 \mu \mathrm{M})$ with the absence or presence of AGBE $(0.5,1.0 \mathrm{mg} / \mathrm{ml})$ for 24,48 and $72 \mathrm{~h}$. The cell stained with cyclin A-FITC and proidium iodide. The percentage of cyclin A-positive cells is shown in the gate. Data shown are from two independent experiments.

data showed that AGBE markedly reduced the proportion of viable cells, but did not increase the proportion of early apoptotic cells.

Incubation with 5 -FU at $10 \mu \mathrm{M}$ for 24,48 and $72 \mathrm{~h}$ did not alter the number of early apoptotic cells, which was essentially the same as that of the control. In addition the percentage of apoptotic cells in co-treatment groups was not markedly increased compared with that of groups treated with AGBE alone (data not shown). These results suggested that the suppression of the combination of AGBE and 5-FU on the cell growth may not be through apoptotic induction.

Effect of AGBE on cell cycle and expression of cyclin A. To examine whether the decrease of proliferation in treated cells is a consequence of the cell cycle being arrested at a specific phase, we analyzed the cell cycle of treated SW-480 cells by flow ctyometry. As shown in Fig. 6A, treatment with AGBE $(0.5 \mathrm{mg} / \mathrm{ml})$ for $72 \mathrm{~h}$ markedly induced the $\mathrm{S}$ phase and $\mathrm{G} 2 / \mathrm{M}$ phase arrest of the cell cycle in a time-dependent manner.

Fig. 6B shows the expression level of cyclin A in SW-480 cells with the exposure of AGBE $(0.5 \mathrm{mg} / \mathrm{ml})$ for 24,48 and
72 h. Compared with untreated cells (control: 24.9\%), the fraction of cyclin A positive cells was increased to $29.3 \%$ at $24 \mathrm{~h}, 51.0 \%$ at $48 \mathrm{~h}$ and $64.4 \%$ at $72 \mathrm{~h}$.

Effect of 5-FU combination with AGBE on cell cycle and expression of cyclin A. As shown in Fig. 7, following the exposure to 5-FU at $10 \mu \mathrm{M}$ for 24,48 and $72 \mathrm{~h}$, the percentage of SW-480 cells at the S phase of the cell cycle increased, and the percentage at the G1 phase decreased compared with the control groups upon the corresponding treated time. The arrest of the cell cycle at $\mathrm{S}$ phase and $\mathrm{G} 2 / \mathrm{M}$ phase was more pronounced in co-treatment groups of 5-FU $(10 \mu \mathrm{M})$ with AGBE $(0.5 \mathrm{mg} / \mathrm{ml})$ than that of 5-FU-treated only group. The percentages at each cell cycle phase upon various treatments are shown in Table I.

The expression of cyclin A in SW-480 cells treated by $5-\mathrm{FU}$ alone and the combination of 5-FU with AGBE is shown in Fig. 8. After incubation with 5-FU, the fraction of cyclin A positive cells increased by $16.3,16.5$ and $17.2 \%$ at 24,48 and $72 \mathrm{~h}$, respectively, compared with the corresponding control group. Combined application of 5-FU and AGBE 
Table I. Percentage of cells in G1, S and G2/M phases.

\begin{tabular}{|c|c|c|c|c|c|c|c|c|c|}
\hline \multirow[b]{2}{*}{ Time } & \multicolumn{3}{|c|}{ Control (\% cells) } & \multicolumn{3}{|c|}{ 5-FU $10 \mu \mathrm{M}(\%$ cells $)$} & \multicolumn{3}{|c|}{$\begin{array}{c}5-\mathrm{FU} 10 \mu \mathrm{M}+\text { AGBE } 0.5 \mathrm{mg} / \mathrm{m} \\
(\% \text { cells })\end{array}$} \\
\hline & $24 \mathrm{~h}$ & $48 \mathrm{~h}$ & $72 \mathrm{~h}$ & $24 \mathrm{~h}$ & $48 \mathrm{~h}$ & $72 \mathrm{~h}$ & $24 \mathrm{~h}$ & $48 \mathrm{~h}$ & $72 \mathrm{~h}$ \\
\hline G1 & 51.2 & 50.4 & 49.1 & 47.0 & 46.2 & 43.6 & 42.5 & 26.5 & 24.3 \\
\hline S & 35.6 & 37.7 & 41.1 & 44.0 & 43.4 & 44.3 & 44.8 & 53.2 & 59.9 \\
\hline $\mathrm{G} 2 / \mathrm{M}$ & 13.2 & 11.9 & 9.8 & 9.0 & 10.3 & 12.2 & 12.7 & 20.3 & 15.8 \\
\hline
\end{tabular}

increased the expression of cyclin A more effectively than $5-\mathrm{FU}$ alone. Both the assays suggested that AGBE could heighten 5-FU-induced $\mathrm{S}$ and $\mathrm{G} 2 / \mathrm{M}$ phase arrest and the expression of cyclin A in colon cancer cells.

\section{Discussion}

Botanical extracts are a complicated mixture of bioactive compounds. The concentrations of these compounds vary significantly depending on genetics, season, geographical distribution, plant growth, and production and extract processes $(28,29)$. Therefore, botanical analysis is an important issue in the quality assurance of botanical products $(30,31)$. In this study, we used American ginseng from Roland Ginseng, LLC because American ginseng from Wisconsin is a reliable ginseng source (32). The content of the major ginsenosides in American ginseng berry extracts was determined using HPLC to standardize our extracts.

It has been reported that AGBE could attenuate cisplatininduced emesis in a rat model, suggesting that the herb may have value in treating chemotherapy-induced nausea/ vomiting. However, it is not clear whether consuming AGBE with chemotherapy affects the efficacy of chemotherapeutic agents.

In this study, we evaluated the effect of AGBE on enhancing chemopreventive efficacy of 5-FU in human colorectal cancer. The antiproliferative activity was determined by the cell counting method. After treatment for $72 \mathrm{~h}$, the antiproliferation of AGBE (0.1-1.0 mg/ml) on SW-480, HCT-116, HT-29, all of which are human colorectal cancer cell lines, were observed in a dose-dependent manner. As expected, 5-FU showed significant inhibition on the proliferation of colorectal cancer cells. The investigation on the influence of AGBE $(0.5$ and $1.0 \mathrm{mg} / \mathrm{ml})$ on 5 -FU-induced antiproliferation in SW-480, HCT-116 and HT-29 cell lines indicated that the cell growth decreased more with the combined treatment than that with 5-FU or AGBE alone. These results suggested that AGBE may reduce the dose of 5-FU needed to achieve desired effects in combination therapy and thereby decrease the dose-related toxicity caused by 5 -FU. To elucidate the potential mechanism of the enhancement of AGBE on the 5-FU-induced antiproliferation in human colorectal cancer cells, we assayed cell apoptosis, cell cycle transition and cycline A expression in SW-480 cells by flow cytometry.

Apoptosis is a homeostatic mechanism that balances cell division and cell death to maintain the appropriate number of cells in the body. Inducing apoptosis is considered an important pathway by which many anticancer agents exhibit the growth inhibition of cancer cells (33-35). However, this study showed that neither AGBE or 5-FU alone nor cotreatment exhibited obvious induction on early apoptosis, which is considered real apoptosis. Thus, apoptotic induction was not involved in the antiproliferative effect of 5-FU combined with AGBE on human colorectal cancer cells.

In our study, AGBE arrested SW-480 cells in the S and G2/M phases, which may trigger the DNA repair mechanism, leading to apoptosis. To obtain further information on the molecular mechanism involved in the arrest of the cell cycle in the $\mathrm{S}$ and $\mathrm{G} 2 / \mathrm{M}$, we determined the expression of cyclin A, which is one of the cyclin family proteins that regulate cell cycle progression, and is required for S-phase and the passage through G2 (36). The fraction of cyclin A positive cells increased to $64.4 \%$ after treatment with AGBE for $72 \mathrm{~h}$ ( $24.9 \%$ in untreated cells). 5-FU, a pyrimidine analog, is generally believed to induce G1-S-phase arrest via inhibition of thymidylate synthase, a key enzyme in DNA synthesis (37). The current data showed that the treatment with $10 \mu \mathrm{M}$ of 5-FU arrested the SW-480 cells specifically in the S-phase. Co-treatment of $10 \mu \mathrm{M}$ of $5-\mathrm{FU}$ and $0.5 \mathrm{mg} / \mathrm{ml}$ of AGBE produced alteration on the cell cycle profile, which displayed an increase of the cell percentage in the G2/M-phase and cell accumulation in the $\mathrm{S}$ phase concurrently as compared to the treatment with 5-FU alone. Similarly, the expression of cyclin A in combination treatment group was much higher than that in 5-FU group. Taken together, the results indicated that AGBE not only has an additive effect on 5-FU-stimulated arrest at the $\mathrm{G} 2 / \mathrm{M}$ in cell cycle progression, but also heighten the arrest of colon cancer cells in the S-phase induced by $5-\mathrm{FU}$.

The successful treatment regimens for cancer include combination chemotherapy, which is often more effective than single chemotherapy because of additive or synergistic effects. In the present study, we evaluated the effects of AGBE in enhancing the chemopreventive efficacy of 5-FU on human colorectal cancer cells. Our data suggest that AGBE has the potential to heighten the tumoricidal effects of 5-FU and that 5-FU-induced antiproliferation of human colorectal cancer cells can be strengthened by combination with AGBE. The mechanism may include the enhancement of AGBE on the $S$ and $\mathrm{G} 2 / \mathrm{M}$ phases arrest and the expression level of cyclin $\mathrm{A}$, but not the induction of cell apoptosis. These results partly suggested that AGBE potentiates the tumoricidal effects of 5-FU, and therefore a lower dose of 5-FU can be used, thereby decreasing the dose-related toxicity caused by 5-FU. Further in vitro and in vivo studies to test AGBE as a chemo-adjuvant are needed. Data obtained from these studies will have the 
potential to help develop advanced treatment regimens for human colorectal cancer.

\section{Acknowledgements}

This study was supported in part by the NIH grants AT003255, AT004418, GM074197, CA106569 and 5P30DK042086, and from the American Cancer Society RSG-05-230-01DDC and RSG-05-254-01DDC.

\section{References}

1. Csejtei A, Tibold A, Varga Z, et al: GSTM, GSTT and p53 polymorphisms as modifiers of clinical outcome in colorectal cancer. Anticancer Res 28: 1917-1922, 2008.

2. Delval L and Klastersky J: Optic neuropathy in cancer patients. Report of a case possibly related to 5-fluorouracil toxicity and review of the literature. J Neurooncol 60: 165-169, 2002.

3. Viale PH and Yamamoto DS: Cardiovascular toxicity associated with cancer treatment. Clin J Oncol Nurs 12: 627-638, 2008

4. Patel BB, Sengupta R, Qazi S, et al: Curcumin enhances the effects of 5-fluorouracil and oxaliplatin in mediating growth inhibition of colon cancer cells by modulating EGFR and IGF-1R. Int J Cancer 122: 267-273, 2008.

5. Politano S, Overman M, Pathak P, et al: Second-line chemotherapy use in metastatic colon cancer varies by disease responsiveness. Clin Colorectal Cancer 7: 55-59, 2008.

6. Sheikh HY, Valle JW, Waddell T, et al: Alternating irinotecan with oxaliplatin combined with UFT plus leucovorin (SCOUT) in metastatic colorectal cancer. Br J Cancer 99: 577-583, 2008.

7. Kim YJ, Kang SA, Hong MS, et al: Coptidis rhizoma induces apoptosis in human colorectal cancer cells SNU-C4. Am J Chin Med 32: 873-882, 2004.

8. Luo JZ and Luo L: Ginseng on hyperglycemia: Effects and mechanisms. Evid Based Complement Alternat Med (In Press).

9. Vuksan V, Stavro MP, Sievenpiper JL, et al: American ginseng improves glycemia in individuals with normal glucose tolerance: effect of dose and time escalation. J Am Coll Nutr 19: 738-744, 2000.

10. Duda RB, Zhong Y, Navas V, et al: American ginseng and breast cancer therapeutic agents synergistically inhibit MCF-7 breast cancer cell growth. J Surg Oncol 72: 230-239, 1999.

11. King ML and Murphy LL: American ginseng (Panax quinquefolius L.) extract alters mitogen-activated protein kinase cell signaling and inhibits proliferation of MCF-7 cells. J Exp Ther Oncol 6: 147-155, 2007.

12. Luo X, Wang CZ, Chen J, et al: Characterization of gene expression regulated by American ginseng and ginsenoside Rg3 in human colorectal cancer cells. Int J Oncol 32: 975-983, 2008.

13. Wang CZ and Yuan CS: Potential role of ginseng in the treatment of colorectal cancer. Am J Chin Med 36: 1019-1028, 2008.

14. Wang CZ, Mehendale SR and Yuan CS: Commonly used antioxidant botanicals: active constituents and their potential role in cardiovascular illness. Am J Chin Med 35: 543-558, 2007.

15. Xie JT, McHendale S and Yuan CS: Ginseng and diabetes. Am J Chin Med 33: 397-404, 2005.

16. Wang CZ, Wu JA, McEntee E, et al: Saponins composition in American ginseng leaf and berry assayed by high-performance liquid chromatography. J Agric Food Chem 54: 2261-2266, 2006.
17. Attele AS, Zhou YP, Xie JT, et al: Antidiabetic effects of Panax ginseng berry extract and the identification of an effective component. Diabetes 51: 1851-1858, 2002.

18. Xie JT, Aung HH, Wu JA, et al: Effects of American ginseng berry extract on blood glucose levels in ob/ob mice. Am J Chin Med 30: 187-194, 2002.

19. Xie JT, Wang CZ, Ni M, et al: American ginseng berry juice intake reduces blood glucose and body weight in ob/ob mice. J Food Sci 72: S590-S594, 2007.

20. Mehendale SR, Wang CZ, Shao ZH, et al: Chronic pretreatment with American ginseng berry and its polyphenolic constituents attenuate oxidant stress in cardiomyocytes. Eur J Pharmacol 553: 209-214, 2006.

21. Mehendale S, Aung H, Wang A, et al: American ginseng berry extract and ginsenoside Re attenuate cisplatin-induced kaolin intake in rats. Cancer Chemother Pharmacol 56: 63-69, 2005.

22. Aung HH, Mehendale SR, Wang CZ, et al: Cisplatin's tumoricidal effect on human breast carcinoma MCF-7 cells was not attenuated by American ginseng. Cancer Chemother Pharmacol 59: 369-374, 2007.

23. Wang CZ, Zhang B, Song WX, et al: Steamed American ginseng berry: ginsenoside analyses and anticancer activities. J Agric Food Chem 54: 9936-9942, 2006.

24. Pinedo HM and Peters GF: Fluorouracil: biochemistry and pharmacology. J Clin Oncol 6: 1653-1664, 1988.

25. Smorenburg CH, Peters GJ, van Groeningen CJ, et al: Phase II study of tailored chemotherapy for advanced colorectal cancer with either 5-fluouracil and leucovorin or oxaliplatin and irinotecan based on the expression of thymidylate synthase and dihydropyrimidine dehydrogenase. Ann Oncol 17: 35-42, 2006.

26. Wolpin BM and Mayer RJ: Systemic treatment of colorectal cancer. Gastroenterology 134: 1296-1310, 2008.

27. Meregalli M, Martignoni G, Frontini L, et al: Increasing doses of 5-fluorouracil and high-dose folinic acid in the treatment of metastatic colorectal cancer. Tumori 84: 662-665, 1998.

28. Ang-Lee MK, Moss J and Yuan CS: Herbal medicines and perioperative care. JAMA 286: 208-216, 2001.

29. Ernst E: The risk-benefit profile of commonly used herbal therapies: Ginkgo, St. John's Wort, Ginseng, Echinacea, Saw Palmetto, and Kava. Ann Intern Med 136: 42-53, 2002.

30. Wang CZ, Li P, Ding JY, et al: Discrimination of Lonicera japonica THUNB. from different geographical origins using restriction fragment length polymorphism analysis. Biol Pharm Bull 30: 779-782, 2007.

31. Wang CZ, Li P, Ding JY, et al: Simultaneous identification of Bulbus Fritillariae cirrhosae using PCR-RFLP analysis. Phytomedicine 14: 628-632, 2007

32. Assinewe VA, Baum BR, Gagnon D, et al: Phytochemistry of wild populations of Panax quinquefolius L. (North American ginseng). J Agric Food Chem 51: 4549-4553, 2003.

33. Reed JC and Pellecchia M: Apoptosis-based therapies for hematologic malignancies. Blood 106: 408-418, 2005.

34. Wu WY, Guo HZ, Qu GQ, et al: Mechanisms of pseudolaric Acid B-induced apoptosis in bel-7402 cell lines. Am J Chin Med 34: 887-899, 2006.

35. Moon PD, Koo HN, Jeong HJ, et al: Haeamtang induces apoptosis of colon cancer HT-29 cells through activation of caspase-3. Am J Chin Med 35: 897-909, 2007.

36. Nakayama KI and Nakayama K: Ubiquitin ligases: cell-cycle control and cancer. Nat Rev Cancer 6: 369-381, 2006.

37. Yoshikawa R, Kusunoki M, Yanagi H, et al: Dual antitumor effects of 5-fluorouracil on the cell cycle in colorectal carcinoma cells: a novel target mechanism concept for pharmacokinetic modulating chemotherapy. Cancer Res 61: 1029-1037, 2001. 